\title{
Operative Anatomy, Third Edition, Carol E. H. Scott-Conner and David L. Dawson
}

\author{
Lippincott Williams \& Wilkins, Philadelphia, PA, 768 pp, \$US140, ISBN-10: \\ 0781765390 (amazon.com)
}

\author{
Adam Klipfel
}

Published online: 16 September 2009

(C) Société Internationale de Chirurgie 2009

This text, like the two previous editions, provides the reader with relevant, procedure-specific, operative anatomy, including potential complications and safety elements. It includes more than 110 procedures, both open and laparoscopic, from all areas of the body. This text will be useful for surgeons from all specialty areas but especially for the general surgeon with a comprehensive and inclusive practice and for residents and fellows in surgery.

The content and organization of this third edition has been improved by the addition of a section of highlights with two new key elements at the beginning of each chapter. The first edition had a "List of Structures," which was interesting in terms of the anatomy, but the two new elements at the beginning of each chapter- "Steps in Procedure" and "Hallmark Anatomic Complications"provide orientation and focus on the most important aspects of each chapter and thus each surgical procedure. This is a unique feature, one that I wish had appeared in textbooks when I was a resident reading for operative cases, or for the Medical Boards.

The introduction to each chapter highlights the most relevant aspects of the procedures being presented, making reading more efficient and productive. This focus contrasts with many major textbooks in general surgery, most of which are so comprehensive that they are not useful for a quick read or review before an operation. In addition, the major texts do not contain sections that detail the specific steps relevant to an operation.

Because of its special features, this text is useful for a preoperative review or just general learning about operative

\footnotetext{
A. Klipfel ( $₫)$

RI Colorectal Clinic, Brown Medical School, 334 East Avenue, Pawtucket, RI 02860, USA

e-mail: aaklipfel@yahoo.com
}

surgery. Each chapter is organized by procedures for a specific area of the body. The chapter then presents the details of the procedure, including the step-by-step description, as well as various pitfalls that may be encountered.

Another very useful aspect of this text is the on-line access to the entire text and images. This is especially useful for a resident or attending surgeon who is in the hospital and has time between cases to refresh and review the anatomy and the surgical approach prior to a procedure.

The majority of the images in the book are relevant and easy to understand; however, there are some in which the details are difficult to see. They could be improved, specifically those in the laparoscopy section, which could also benefit from additional photographs, and even videos. Because of costs, the publisher might resist the addition of videos, but these could be available on-line to purchasers of the text.

Another area that I believe could be improved is the section on instruments. The addition of this chapter was a great idea, but the text needs more information and expansion. For the resident especially to be able to learn the names and uses of the various instruments could be helpful in preparation for the operating room.

Overall, this is a well conceived and useful textbook. It helps fill a void in surgical educational by combining the factual information of a traditional surgical textbook with the descriptive anatomy and visual aids of a surgical atlas. I highly recommend this text to practicing general surgeons in any area of the world. It will be particularly useful for residents and fellows. I look forward to the authors' continuing to expand and enhance further editions of this valuable book. 